\title{
T cells in the control of organ-specific autoimmunity
}

\author{
Jeffrey A. Bluestone, Hélène Bour-Jordan, Mickie Cheng, and Mark Anderson \\ Diabetes Center, UCSF, San Francisco, California, USA.
}

\begin{abstract}
Immune tolerance is critical to the avoidance of unwarranted immune responses against self antigens. Multiple, nonredundant checkpoints are in place to prevent such potentially deleterious autoimmune responses while preserving immunity integral to the fight against foreign pathogens. Nevertheless, a large and growing segment of the population is developing autoimmune diseases. Deciphering cellular and molecular pathways of immune tolerance is an important goal, with the expectation that understanding these pathways will lead to new clinical advances in the treatment of these devastating diseases. The vast majority of autoimmune diseases develop as a consequence of complex mechanisms that depend on genetic, epigenetic, molecular, cellular, and environmental elements and result in alterations in many different checkpoints of tolerance and ultimately in the breakdown of immune tolerance. The manifestations of this breakdown are harmful inflammatory responses in peripheral tissues driven by innate immunity and self antigen-specific pathogenic T and B cells. T cells play a central role in the regulation and initiation of these responses. In this Review we summarize our current understanding of the mechanisms involved in these fundamental checkpoints, the pathways that are defective in autoimmune diseases, and the therapeutic strategies being developed with the goal of restoring immune tolerance.
\end{abstract}

\section{Introduction}

Genetic predisposition for most autoimmune disorders is polygenic and conferred by shared as well as disease-specific alleles. Genome-wide association studies have identified dozens of genetic variants associated with autoimmunity (1). The MHC loci confer the highest genetic risk in many autoimmune diseases, pointing to a critical role for antigen $\mathrm{T}$ cell interactions in disease pathogenesis. Additionally, many of the shared variants have pleiotropic effects on pathways that are important for conventional $\mathrm{T}$ cells (Tconvs) but are also critical for the homeostasis and/or function of Tregs, such as IL-2, CD25, cytotoxic T lymphocyteassociated protein 4 (CTLA4), and protein tyrosine phosphatase, non-receptor type 22 (2-4). Conversely, disease-specific associations implicate variants for genes either encoding major autoantigens or that are involved in their generation $(5,6)$. Although beyond the scope of this Review, rare genetic variants have also been critically informative about the role of innate immunity or other arms of the immune system in systemic autoimmune diseases such as lupus (7), which are beyond the scope of this discussion. Taken together, genetics studies point to the central role of pathways involved in thymic $\mathrm{T}$ cell education and peripheral immunoregulation by Tregs for the control of autoimmune diseases.

Immune tolerance stems from the control of autoreactive T cells both in the thymus and the periphery, owing to mechanisms known as central and peripheral tolerance, respectively. Central tolerance eliminates potentially autoreactive lymphocytes that develop in the thymus by subjecting thymocytes with high affinity

Conflict of interest: Mark Anderson's spouse is a shareholder of Medtronic and Merck. Jeffrey A. Bluestone is a scientific advisor for Juno Therapeutics; a member of the scientific advisory boards of Flexus Biosciences, Kadmon Corporation, Pfizer, and NeoStem (Athelos Division); a shareholder of Macrogenics Inc.; and receives research support from NeoStem.

Reference information: / Clin Invest. 2015;125(6):2250-2260. doi:10.1172/JCI78089. for self antigens to either clonal deletion (negative selection) or selection into the Treg lineage. Many autoreactive T cells escape this checkpoint and can be found in the peripheral blood of healthy individuals; however, these self-reactive cells are not sufficient to induce autoimmunity due to additional controls by peripheral tolerance mechanisms (8-11). Peripheral tolerance is achieved through $\mathrm{T}$ cell-intrinsic mechanisms that lead to clonal deletion, anergy, or immunological ignorance as well as extrinsic control by specialized populations of suppressor cells that regulate potentially harmful responses of autoreactive $\mathrm{T}$ and $\mathrm{B}$ cells $(12,13)$. First among these are $\mathrm{CD} 4^{+} \mathrm{CD} 25^{+} \mathrm{Foxp}^{+}$Tregs, a $\mathrm{T}$ cell population that is essential for extrinsic control of peripheral tolerance $(14,15)$.

Tregs play a fundamental role in inhibiting self-reactivity and maintaining immune tolerance (16). Several types of Tregs have been described, including Foxp3- IL-10-dependent Tr1 cells, $\mathrm{LAP}^{+}$TGF- $\beta$-dependent Th3 cells, and CD8 ${ }^{+}$Tregs; however, in this Review we focus on Tregs that express the transcription factor Foxp3, a "master regulator" of this Treg lineage that is crucial for their homeostasis and function. Loss-of-function mutations in the FOXP3 gene are responsible for immune dysregulation, polyendocrinopathy, enteropathy, X-linked (IPEX) syndrome, which is characterized by widespread and often fatal autoimmunity shortly after birth (17). Similarly, mice deficient in Foxp3 completely lack Tregs and rapidly develop lethal multi-organ autoimmunity $(18,19)$. The requirement for Foxp3 expression in Tregs is quantitative in nature and lifelong, as illustrated by the development of lymphoproliferative disease within days of acute depletion of Foxp $3^{+}$Tregs in adult mice $(20,21)$.

\section{Central tolerance as a key checkpoint}

The generation of an extremely diverse $\mathrm{T}$ cell repertoire in the thymus through stochastic gene rearrangement of the TCR is a powerful weapon in our immunity against pathogens. At the same time, collateral damage can occur when autoreactive T cells 
are generated through this stochastic process, which is a critical challenge in immune tolerance. A key mechanism in maintaining tolerance occurs in the thymic medulla, where self antigens are presented to developing $\mathrm{T}$ cells by both medullary thymic epithelial cells (mTECs) and resident bone marrow-derived APCs. mTECs have the unusual property of expressing a wide array of tissue-specific self antigens (TSAs), which shape the developing $\mathrm{T}$ cell repertoire. This ectopic antigen expression relies on the autoimmune regulator (Aire) gene (22-24); patients with defects in Aire succumb to an autoimmune syndrome termed autoimmune polyglandular syndrome type 1 , which is characterized by multiorgan immune infiltrates and autoantibodies (25). Tolerance against TSAs, through clonal deletion and Treg development in the thymus, appears to be remarkably efficient (Figure 1). Animal models of Aire deficiency have shown that $\mathrm{T}$ cells specific for thymic TSAs are virtually undetectable in the periphery when Aire is functional (26). Additionally, the relevance of TSA display within the thymus to autoimmune diseases is supported by genetic studies that have linked variants affecting thymic expression of human insulin and the acetylcholine receptor to susceptibility for type 1 diabetes (T1D) and myasthenia gravis, respectively $(5,27,28)$.

Interestingly, tolerance-inducing mTECs rapidly turn over, with a half-life of 12-14 days in adult mice (29). After genetic cell ablation, Aire ${ }^{+}$mTECs recover within three to five days (30), suggesting a significant reserve of resident thymic epithelial stem cells, recently identified as a Sca1-expressing thymic epithelial cell population $(31,32)$. Importantly, the RANK/RANKL signaling pathway is a major factor in this process (33-35). Treatment with anti-RANKL mAb results in deletion of Aire-expressing mTECs and preserves the positively selecting cortical epithelial compartment. Consistent with these results, negative selection of $\mathrm{T}$ cells is perturbed and autoreactive $\mathrm{T}$ cells now escape thymic deletion. The rapid turnover of mTECs likely represents an important mechanism to help ensure the continuous display of diverse self antigens to developing $\mathrm{T}$ cells. While the human thymus undergoes involution with age, increases in thymopoiesis can be seen following immunodepletion (e.g., with HIV or cytotoxic therapies), and new thymic emigrants can be observed in normal individuals even late in life $(36,37)$, suggesting a contribution for thymic function throughout life. This implies that approaches could be utilized to either enhance or block the thymic negative selection process to improve or break self-tolerance. Notably, these findings also suggest that patients treated with denosumab (an anti-RANKL mAb) should be closely examined for autoimmunity complications.

\section{Self-antigen recognition by autoreactive T cells}

A growing body of work suggests that many autoreactive $\mathrm{T}$ cells have unusual binding properties for their cognate MHC-peptide ligands. Autoreactive T cells with unusual TCR topologies may escape thymic deletion due to aberrant/reduced binding to the MHC that is insufficient to trigger apoptosis (38). Structural analyses of TCRs from patients with MS and T1D have revealed this property of autoreactive TCRs specific for disease-specific self-peptides, such as myelin basic protein and insulin $(39,40)$. Additionally, the processing and presentation of peptides plays a large role in shaping the $\mathrm{T}$ cell repertoire during thymic education. Recent work from Kappler and colleagues has determined that insulin-specific $\mathrm{CD} 4^{+} \mathrm{T}$ cells in the NOD mouse model have a propensity to react to a peptide of insulin that sits in the MHC groove in the suboptimal of three binding registers $(41,42)$. The affinity of this 15-amino acid peptide derived from the insulin B chain (Ins9-23) for the NOD mouse MHC class II allele, $\mathrm{I}-\mathrm{Ag} 7$, is relatively weak. An I-Ag7/Ins9-23-optimized peptide tetramer locked into the least favored register reacts with multiple $\mathrm{T}$ cells enriched in the islets of prediabetic mice. This work has now been translated to human subjects with T1D that have DQ8-restricted insulin-specific T cells (43). Recent work from the Unanue group has suggested that this type of peptide-MHC complex may involve insulin peptide-loading events that uniquely occur in pancreatic islets but not in normal APCs (44, $45)$. In support of this hypothesis, when whole insulin protein is provided to normal APCs, many Ins9-23-reactive T cells do not respond; however, they can respond when peptide is presented to them or antigen is provided from whole pancreatic islets $(44,45)$. These studies suggest that $\mathrm{T}$ cells that recognize insulin peptides in higher-affinity binding registers are efficiently deleted in the thymus, perhaps in an Aire-dependent manner.

In addition to the example of insulin, there are also documented cases of myelin epitopes and other islet antigen epitopes, in which the antigenic peptide recognized by autoreactive T cells is sitting in the MHC binding groove in an unusual fashion (46-49). Moreover, a recent study in humans suggests that epitope presentation within the target tissue may affect the response of pathogenic $\mathrm{CD}^{+} \mathrm{T}$ cells. Indeed, a 9-mer peptide of glutamate carboxylase 65 is not generated by the endogenous pathway of antigen processing in islets in normal conditions but is recognized by some autoreactive $\mathrm{CD}^{+} \mathrm{T}$ cells and forms complexes with MHC class I molecules that are more stable than those formed with the longer, naturally presented 10-mer peptide (50). Likewise, the ability of certain MHC types to accommodate posttranslationally modified peptides may be part of the basis for T cell autoreactivity in RA and celiac disease $(51,52)$. A potential key commonality to these findings is the strong imposition of thymic tolerance on the immune repertoire and autoreactive $\mathrm{T}$ cell specificities that often involve a mismatch with the self antigens displayed in the thymus.

\section{Thymic Treg selection}

In addition to its role in promoting deletion of autoreactive $\mathrm{T}$ cells, the thymus can also help to prevent autoimmunity by promoting the positive selection of Foxp $3^{+}$Tregs (Figure 1). During thymic selection the small subpopulation of $\mathrm{CD}^{+} \mathrm{T}$ cells that express Foxp3 is selected on high-affinity peptides in a selective thymic niche (53). Although multiple APC populations in the thymus likely contribute to Treg selection (54), studies have suggested a potential role for Aire in this process (55-57). Using a limited $\mathrm{T}$ cell repertoire system in mice, the Hsieh group sequenced a large number of TCR sequences in the presence or absence of Aire and of individual APC populations in the thymus (55). Aire expression controlled selective expression of certain Treg sequences through the direct expression of self antigens by mTECs. However, a significant fraction of Tregs develop in an Aire-independent manner, which explains in part why Treg frequencies are relatively normal in Aire-deficient mice (58). Looking forward, it will be interesting to determine the actual antigen specificities of the Treg TCRs that 


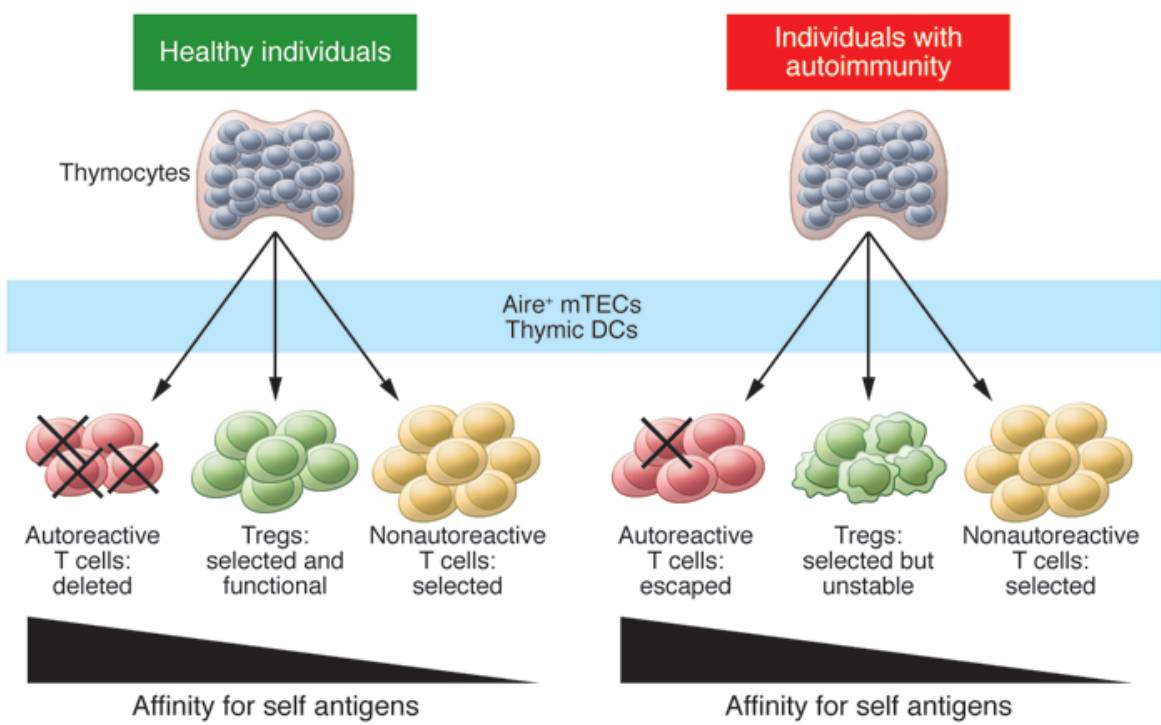

Figure 1. Defects in both central and peripheral tolerance contribute to the development of autoimmunity. Left: In healthy individuals, most developing thymocytes with highly self-reactive TCRs are deleted during negative selection, while nonautoreactive cells mature and leave the thymus. Tregs are also selected on self antigens and express TCRs with higher affinity for self antigens than do Tconvs. The presentation of self antigens to developing thymocytes by Aire ${ }^{+}$mTECs and thymic DCs is integral to the negative selection of autoreactive T cells and the generation of Tregs. Upon thymic selection, these Tregs migrate to the periphery, where they play a central role in maintaining peripheral tolerance, notably by controlling autoreactive T cells that escaped negative selection. Right: In contrast, in individuals with autoimmune diseases, Tregs demonstrate epigenetic, transcriptional, and functional features of instability that may result in loss of Foxp3 expression and suppressive function. These "ex-Foxp3" cells remain skewed toward autoreactivity and, in the absence of Foxp3 expression, can produce pro-inflammatory cytokines that may contribute to the pathological destruction of peripheral tissues. Moreover, Tregs are inefficient at controlling autoreactive T cells that escaped negative selection and are more prone to activation in the periphery due to defects in presentation of self antigens in the thymus.

are Aire dependent and why these cells adopt the Treg fate rather than one of deletion.

\section{Tregs in tolerance and autoimmunity}

Many studies have uncovered alterations in the Treg compartment in autoimmune diseases. In mice, experimental manipulation of Tregs has profound effects on the incidence, onset, and severity of autoimmune diseases. Reducing the number or function of Tregs results in exacerbation of disease, whereas replenishing defective Treg populations is beneficial in mouse models of T1D, MS, SLE, or inflammatory bowel disease (IBD) (59-61). Additionally, the evolution of several autoimmune diseases mirrors qualitative changes that occur over time in autoreactive effector $\mathrm{T}$ cells (Teffs) and that affect their ability to be controlled by Tregs (62-64). Thus, the development of autoimmunity reflects alterations in both pathogenic $T$ cells and Tregs, underlining the fact that a proper balance of Teffs and Tregs is critical to achieve and maintain peripheral tolerance (65). In humans, defects in the number, phenotype, and/or function of Tregs have been described in many autoimmune diseases, including T1D and MS $(15,66,67)$. Defective STAT5 phosphorylation upon IL-2 signaling, which has been observed in patients with T1D and MS, may alter Foxp3 expression and contribute to the loss of peripheral tolerance and development of autoimmunity (refs. 68-70 and Figure 1). Of note, it has sometimes been challenging to reach a consensus on the nature and extent of Treg defects in T1D and other autoimmune diseases because of conflicting reports on the number of circulating Tregs and their in vitro suppressive ability in T1D patients compared with healthy controls (15, 71-74). These discrepancies may be related in part to the absence of a unique Treg lineage marker, the lack of in vitro assays that faithfully reflect in vivo suppressive function (75), and, in most cases, the fact that the only cells available from human subjects are PBMCs, which may not always be appropriate to reveal tissue-specific Treg defects (76).

\section{Immunoregulation by distinct subsets of Tregs}

Tregs develop both as a specialized subset in the thymus (tTregs) as described above (77, 78) and as a consequence of Foxp3 induction in Tconvs upon exposure to antigens in the periphery (pTregs), either in steady state or following tolerogenic treatments (79-83). The developmental pathways of both tTregs and pTregs share requirements for TCR stimulation and IL-2 signaling. TGF- $\beta$ and retinoic acid are critical for the generation of pTregs and are likely involved in the preferential induction of pTregs in mucosal surfaces, notably the intestinal mucosa (84-87). Commensal bacteria are instrumental in the generation of large numbers of colonic pTregs, as bacteria in the gut provide a TGF- $\beta$-rich environment and produce metabolites that induce epigenetic modifications that promote differentiation of Tconvs into pTregs (88-91). It is unclear whether a specific tissue niche is related to the unique features and requirements of the gut or whether it results from tissue-specific mechanisms for maintaining peripheral tolerance in distinct tissues.

While both tTregs and pTregs can efficiently suppress Tconv responses in vitro, their respective roles in peripheral tolerance remain controversial (92). Accumulating evidence suggests that both tTregs and $\mathrm{pTregs}$ are required to prevent autoimmunity under certain inflammatory conditions (93-95). A lack of pTregs has been associated with inflammation at mucosal sites, even with a normal tTreg compartment $(94,95)$. Conversely, pTregs are capable of controlling islet-specific but not CNS-specific autoreactive T cells, while tTregs can control both (96). This raises the possibility that $\mathrm{pTregs}$ and tTregs may play specialized and complementary roles in peripheral tolerance (81). The TCR repertoire of Tregs and Tconvs is largely distinct and overlaps primarily between Tregs and autoreactive Tconvs (77, 97-99). We further hypothesize that tTregs primarily maintain immune homeostasis by continuously controlling $\mathrm{T}$ cell responses against shared and ubiquitous self antigens, whereas pTregs are generated locally after recognition of TSAs and, due to their limited stability, transiently regulate autoreactive responses in tissues (Figure 2). The 


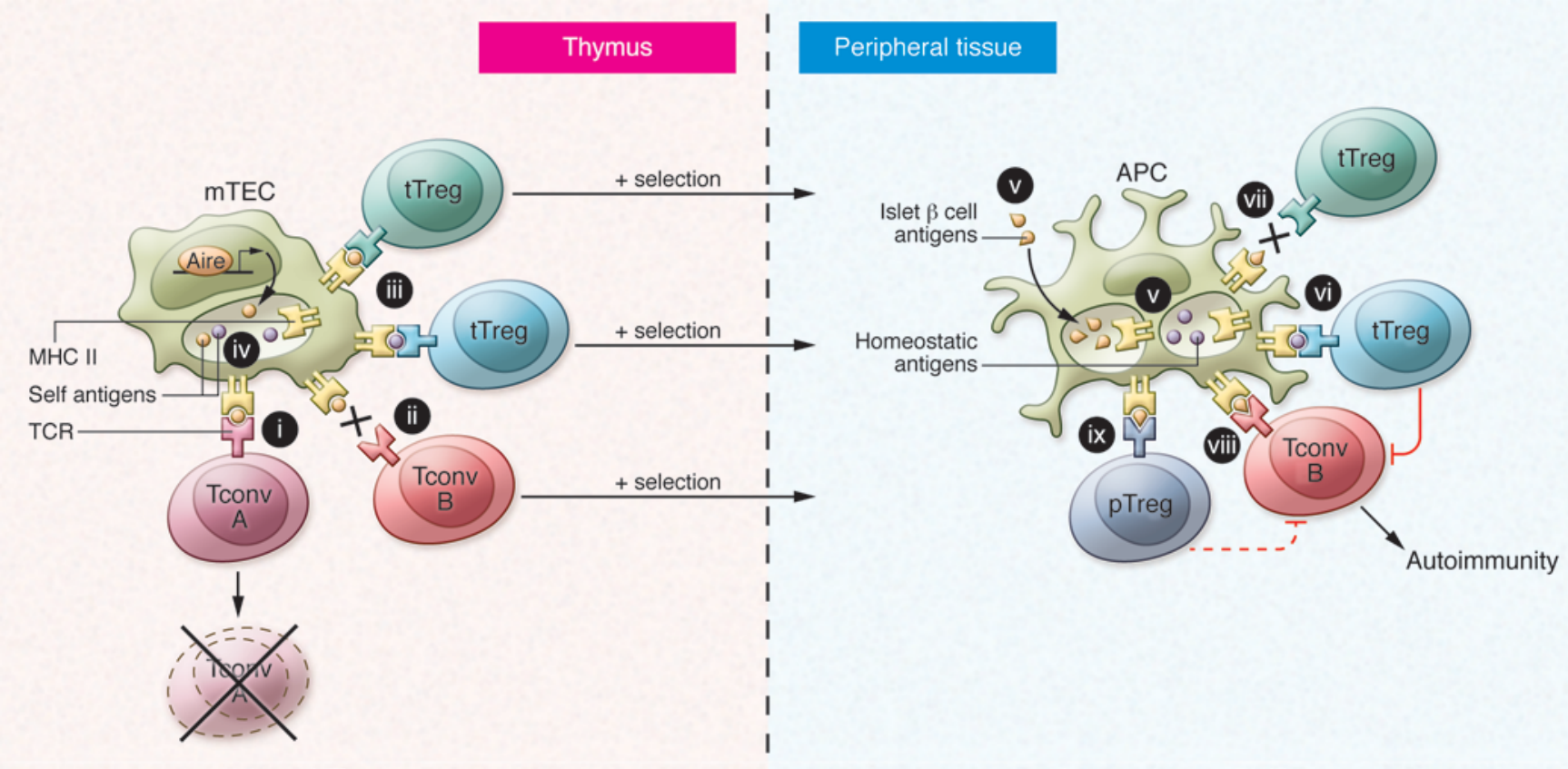

Figure 2. Model for self-peptide presentation in shaping $\mathbf{T}$ cell function and development of autoimmunity. Mounting data support a key role for self-antigen presentation in T cell selection and autoimmunity. Left: In the thymus, CD4+ $T$ cells with high affinity for self antigens undergo apoptosis (Tconv A) (i), while Tconv B escape negative selection (ii) due to low affinity for "classical" stable peptide MHC (pMHC) complexes that are formed by processing and loading of self-proteins onto MHC class II molecules in late endosomes (iv). Tregs arise from thymocytes that interact with self pMHC complexes with a high affinity insufficient to trigger negative selection (iii) and recognize self-peptides both from homeostasis-related tissue nonspecific antigens (pink rectangles) and from tissue-restricted antigens (yellow rectangles), expressed under the control of Aire in mTECs (iv). Right: In the periphery, positively selected Tregs and Tconvs encounter pMHC complexes that only partially overlap with those presented in the thymus (v). Unstable and/or tissue-specific pMHC complexes (v) may arise when extracellular self-peptides bypass classical processing to associate with MHC class II in early endosomes (yellow triangles). Thus, tTregs recognizing homeostasis antigens can be activated in the periphery (vi), whereas tTregs selected on classical pMHC complexes in the thymus cannot recognize the "peculiar" pMHC complexes uniquely generated in the periphery from the same tissue-restricted antigen (vii). These peculiar pMHC complexes can activate autoreactive cells that escaped negative selection (Tconv B) (viii) as well as pTregs generated in the periphery (ix). Thus, the limited diversity and frequency of tTregs in the tissue, combined with reduced stability and efficacy of pTregs in inflamed tissues, contributes to failure of local immunoregulation of autoreactive Tconv cells and resultant autoimmunity.

functional differences and limited TCR overlap between tTregs and pTregs expand the overall diversity of the Treg repertoire and may be central to the requirement for both populations for proper regulation of immune responses against diverse self antigens and foreign antigens.

Based on these studies, the overall emerging model postulates that $\mathrm{t}$ Tregs and pTregs synergize to prevent autoimmunity in peripheral tissues of healthy individuals thanks to their complementary repertoire and functional capabilities. In individuals prone to autoimmunity, as described above, the presence of unique self-peptide/MHC complexes in tissues that are not present in the thymus implies that tTregs may recognize a set of self antigens in the thymus that is distinct from self antigens presented in the periphery, thus affecting their ability to control autoimmune responses. While pTregs may in turn be able to recognize this unique set of peripheral self antigens, the greater instability of pTregs compared with tTregs may prevent the effective control of autoreactive $\mathrm{T}$ cells in inflammatory settings. Thus, peripheral TCR "reshaping" of Treg repertoires may play a role in the ability of Tregs to recognize self antigens in a given target tissue to protect that tissue from autoimmunity $(100,101)$. However, an inadequate repertoire of tTregs combined with impaired stability and function of pTregs in the inflammatory setting may contribute to autoimmunity (Figure 2).

\section{Stability of Tregs}

Whereas the majority of Tregs remain Foxp $3^{+}$, a subset may become unstable and lose Foxp3 expression in inflammatory or lymphopenic conditions $(102,103)$. For example, $\mathrm{CD}^{+}{ }^{+} \mathrm{Foxp}^{+}$Tregs can be reprogrammed to produce IL-17 and IFN- $\gamma$ in inflammatory environments in mice and humans $(76,104,105)$. These "ex-Foxp3" cells can mediate autoimmunity in mouse models of autoimmune diabetes and arthritis $(102,106)$. Of note, the stability of Tregs has been a controversial topic, as other studies concluded that fully differentiated Tregs were stable while ex-Foxp3 cells were derived from loosely committed Tregs; however, these studies were not performed in the setting of autoimmunity $(107,108)$. Conversely, in the EAE model of MS, loss of Foxp3 and Treg instability were observed in bona fide Tregs and occurred predominantly in autoreactive Tregs in the context of self antigen-driven activation and inflammation (109). Moreover, similar phenomena of Treg plasticity and instability have been described in humans with T1D, RA, and MS and correspond to distinct molecular stages with discrete epigenetic and gene expression signatures $(106,110,111)$. 


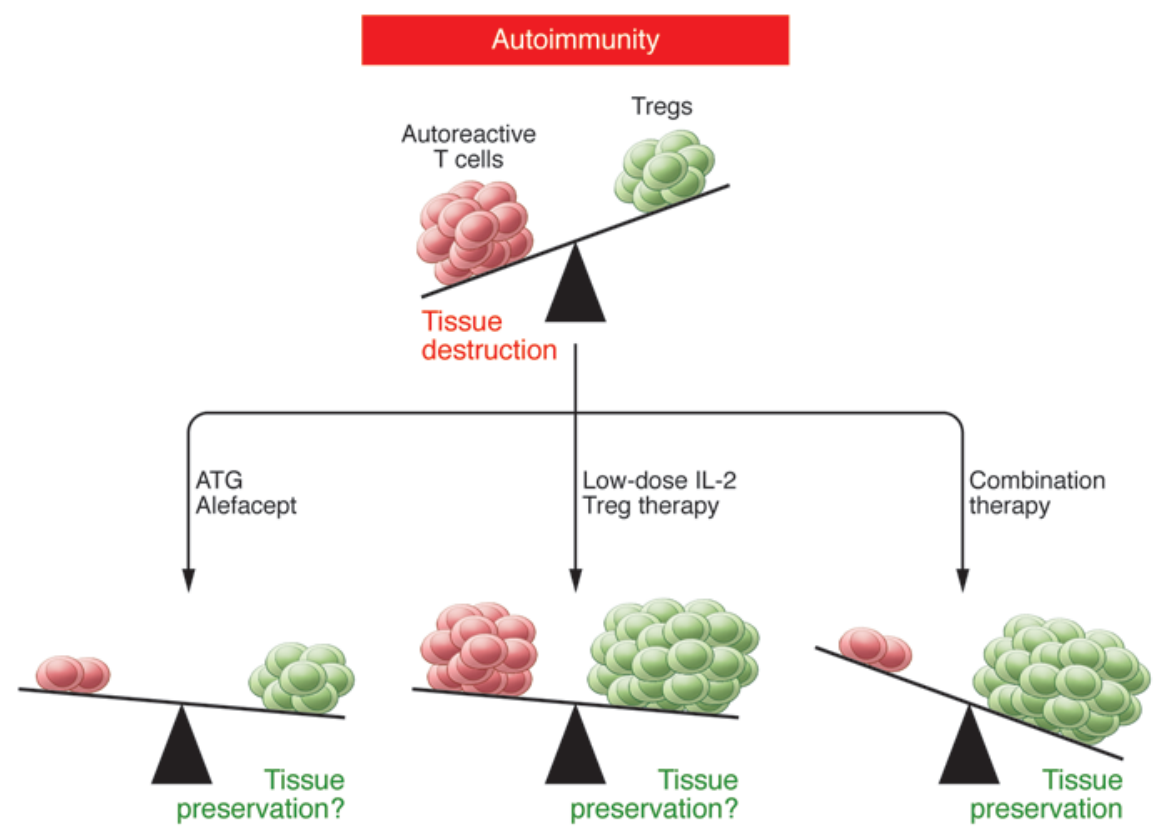

Regulation

Figure 3. Therapeutic strategies to restore the balance of pathogenic versus Treg responses in autoimmunity. Autoimmune diseases result from an imbalance of pathogenic autoreactive Tconv cells and protective Tregs. Many immunotherapies for autoimmune diseases share a common goal of restoring immune tolerance but employ different strategies to skew the balance of immune responses toward dominant Treg-mediated regulation. Some systemic therapies, such as ATC or alefacept, reset the balance by inducing a massive but selective deletion of Tconvs, including autoreactive T cells. Conversely, more recent approaches such as low-dose IL-2 or Treg cellular therapy are aimed at boosting the number and/or function of Tregs to a point where they are able to control autoreactive T cells. While both types of approaches have been successful in animal models and sporadically in humans, these monotherapies have thus far been largely ineffective at permanently curing autoimmune diseases. This has led to the notion that combination therapies that both eliminate autoreactive T cells and repair Treg defects may be necessary to sufficiently shift the immune scale toward regulation and durably reestablish tolerance.

Mechanistically, the primary prerequisite for the maintenance of the Treg population is stable Foxp3 expression $(20,112)$. The requirements for Foxp3 expression in Tregs include signaling through co-stimulatory and cytokine receptors (113-116). TCR/ CD28 and IL-2R signaling are not only required for Treg development and homeostasis but are critical for their suppressive function $(117,118)$. In particular, signaling through IL-2R is critical for maintaining Foxp3 expression and Treg homeostasis (119). A Foxp3 intronic element known as the conserved noncoding sequence 2 (CNS2; also referred to as Treg-specific demethylated region) is highly demethylated in Tregs but completely methylated in other T cell lineages (120-122). CNS2 is important to stabilize Foxp3 expression upon Treg stimulation and division in inflammatory environments or conditions of limited IL-2 $(123,124)$. Importantly, CNS2 ensures stable inheritance of Foxp3 expression and maintains Treg lineage identity by acting as a sensor of TCR/ NFAT and IL-2/STAT5 signals.

Finally, the issues of Treg plasticity and stability have important implications in the context of therapeutic approaches in autoimmune diseases. The potential instability of a fraction of Tregs may result in acceleration of disease after Treg- based therapy, which raises concerns about application of this approach to diseases such as MS, in which the continued destruction of vital tissue might lead to increased morbidity. Thus, an important goal for Treg-based therapy as well as therapies designed to improve Treg-mediated suppression will be to generate an environment that may alter the Treg transcriptome and possibly favor the stability of the Treg lineage.

\section{Therapeutic strategies to restore tolerance}

Many therapeutic approaches are aimed at recalibrating pathogenic/regulatory immune pathways to restore tolerance without compromising anti-pathogen defenses (Figure 3). To date, few immunotherapies have achieved immune tolerance, i.e., non-responsiveness to self antigens, without continuous immunosuppression. Coupled with the difficulty in designing effective clinical trials or testing of unlicensed combination therapies in patients, many barriers remain in realizing clinical tolerance induction and merit more critical discussion in the future. Below, we discuss the strides in the last decade that are leading to development of novel strategies aimed at restoring tolerance (125).

Systemic, nonspecific immunotherapies primarily targeting pathogenic autoreactive Teffs. Immunomodulatory therapies that target autoreactive Teffs are designed to work in part by deleting pathogenic cells, with the goal of "resetting" the immune system toward a more balanced homeostasis (126). Given that Tregs work in a dominant manner through bystander suppression and induce "infectious tolerance" (127), many immunotherapies currently under development target Treg defects identified in preclinical studies, with the goal of restoring Treg function $(15,128)$. Antithymocyte globulin (ATG) has shown promising results in NOD mice and a small clinical trial in patients with T1D $(129,130)$ with tolerogenic potential suggested by its favorable effect on the Treg compartment in mice and humans (130-132). Recent phase II trials in patients with new-onset T1D showed no clear benefit for ATG monotherapy (133); however, a combination of low-dose ATG and G-CSF tended to preserve $\beta$ cell function at 12 months following initiation of therapy (134). The disappointing outcome of ATG monotherapy may be due to ineffectual depletion of effector memory $\mathrm{T}$ cells, which are particularly resistant to deletion or suppression $(135,136)$, and suggests that eliminating these cells will be required for successful approaches. Similarly, targeting of CD52 by alemtuzumab, recently approved for relapsing-remitting MS, causes depletion of T and B cells, with subsequent repopulation through preferential homeostatic 
proliferation of pTregs and effector memory T cells (137-139). This selective expansion of $\mathrm{T}$ cell subsets may account for both the drug's efficacy and the high rate of other autoimmune conditions seen in up to one-third of treated patients (140). Likewise, CD2 is expressed on almost all human T cells but is most highly expressed in memory and pathogenic Teffs in autoimmunity $(141,142)$. Treatment of psoriasis patients with a CD2 ligand-specific Fc fusion protein (alefacept) resulted in sustained remissions even after drug discontinuation in some patients (143, 144). Mechanistically, alefacept preferentially depletes effector memory $\mathrm{T}$ cells without eliminating Tregs $(141,145)$. Recently, treatment of T1D with alefacept has shown promise, with some evidence of efficacy in a phase II clinical trial (146). Treatment with Fc receptor non-binding anti-CD3 mAbs teplizumab or otelixizumab in patients with new-onset T1D preserved $\beta$ cell function for up to two years; however, neither mAb ultimately prevented the destruction of the remaining $\beta$ cells (147-150). The mechanisms of action of anti-CD3 mAbs remain unclear but include the selective depletion of activated $\mathrm{T}$ cells and induction or preferential retention of cells with regulatory properties (151-155).

Antigen-specific tolerogenic therapies are expected to be safer than nonspecific strategies due to a lower risk of global immunosuppression (125). Antigen therapy has successfully prevented or reversed autoimmune diseases in the NOD and EAE mouse models (156-159), indicating that targeting responses against one or a few self antigens can thwart polyclonal autoimmune responses. Enrichment in Tregs has been observed after antigen immunotherapy in patients with RA and T1D (160-163). Administration of antigen-coupled ethylene carbodiimide-fixed cells (as well as, more recently, antigen-coated beads) has been extremely effective at restoring tolerance in NOD mice and EAE (164-167). Additionally, a recent phase I clinical trial in MS showed that this approach reduced myelin-specific autoreactive $\mathrm{T}$ cell responses in humans (168). Finally, recent studies in T1D have focused on oral antigen delivery to promote tolerance due to postulated Treg induction and clonal anergy/deletional mechanisms (169). Based on a reduction of diabetes incidence in a small set of higher-risk individuals (170), a large-scale study of oral insulin for T1D prevention is currently ongoing (ClinicalTrials.gov identifier NCT00419562).

Immunotherapies aimed at restoring the control of autoimmune responses by Tregs. The central role of IL- 2 in Treg homeostasis and function has led to therapeutic strategies that aim to improve IL-2 signaling in Tregs (171). In NOD and EAE mouse models, treatment with low-dose IL-2 restored high levels of Foxp3 and CD25 expression, improved the stability of Tregs, and prevented or restored the development of autoimmunity $(76,109,172)$. Administration of low-dose IL-2 in new-onset T1D patients did not alter glucose metabolism but did induce a dose-dependent increase in the frequency of Tregs (173). However, dosage may significantly affect the outcome, as low-dose versus high-dose IL-2 therapy differentially promotes Tregs and Tconvs, respectively (174). In fact, in contrast to low-dose IL-2, treatment of NOD mice with high-dose IL-2 accelerated progression of diabetes $(76,175)$. Thus, approaches aimed at boosting Tregs may need to combine IL-2 treatment with therapies targeting pathogenic Teffs. The mTOR inhibitor rapamycin selectively inhibits the proliferation of Th1 and Th17 cells while enhancing Treg survival (176-178). Treatment of patients with new-onset T1D with rapamycin plus low-dose IL-2 resulted in a transient increase in the frequency of Tregs and stable restoration of IL-2 signaling that persisted long after treatment was discontinued (179). However, the combination therapy also transiently impaired $\beta$ cell function and dramatically increased numbers of natural killer cells and eosinophils, which might have adversely impacted pancreatic islet cells. Thus, IL-2 therapy alters a complex cellular network and additional studies will be necessary to design treatments specifically targeting Tregs. Improved knowledge of the structural properties of IL-2 binding to its receptors on different cell types and advances in protein bioengineering may help solve this conundrum via generation of mutated forms of IL-2 that selectively signal in Tregs $(180,181)$.

Cellular therapy to restore tolerance. The favorable therapeutic profile of Tregs has led to strong interest in Treg-based cellular therapy in transplantation and autoimmune diseases (182). Adoptive transfer of Tregs suppressed inflammation and disease in EAE, NOD mice, and mouse models of IBD and SLE $(59,60$, 183-185). Of note, Tregs expanded in vitro were more efficient at controlling autoimmune responses than their freshly isolated counterparts $(184,186)$. We have developed a clinically relevant procedure for generating large numbers of $\mathrm{CD} 4{ }^{+} \mathrm{CD} 127^{\mathrm{lo} /-} \mathrm{CD} 25^{+}$ Tregs without the need for additional selective agents $(71,72$, 187) and used a current good manufacturing practices-compliant method in a phase I clinical trial of Treg administration in T1D patients. We found that autologous ex vivo-expanded Tregs were well tolerated and long lived, and that average C-peptide levels remained stable for up to two years after treatment (ClinicalTrials.gov identifier NCT01210664), consistent with the one-year follow-up data of a small phase I study in children with T1D (188). Future clinical applications may involve the use of genetically modified Tregs that express genes that promote their survival, stability, trafficking, or suppressive function. In models of diabetes, tissue antigen-specific Tregs are more efficient than polyclonal cells at suppressing autoimmunity $(184,189)$. However, selective expansion of autoantigen-specific Tregs is challenging because of their low precursor frequency and the uncertainty of which antigens to target in most diseases. Redirecting polyclonal Tregs by engineering expression of antigen-specific receptors may help bridge this gap and may also circumvent Treg inefficiencies related to expression of inadequate TCR repertoires, as we and others have recently shown (190-193). These findings support the notion that polyclonal human Tregs could be engineered to express TCRs specific for self antigens in the target tissue in order to improve the efficacy of Treg therapy at protecting this tissue (15). Moreover, this approach could be combined with in vitro or in vivo treatments aimed at correcting other Treg defects, such as the long-term restoration of IL-2 signaling defects by low-dose IL-2 therapy in vivo (179).

Other appealing approaches in cellular therapy involve the use of tissues generated from human pluripotent stem cells (hPSCs). Given that thymic transplantation offers the potential to establish donor-specific tolerance, hPSCs could be differentiated into both one organ for transplantation (e.g., pancreatic $\beta$ cells for T1D) and a second organ (e.g., the thymus) to ensure graft-specific tolerance without the need for sustained immuno- 
suppression $(194,195)$. Coupled with such regenerative strategies, advances in genetic modification of stem cells and iPSCs may soon allow us to engineer thymus or correct defects in order to modulate and enforce tolerance. Although not ready for prime time, these therapeutic strategies have tremendous potential, considering that human embryonic stem cells have recently been used to generate both thymic epithelial progenitors $(196,197)$ and islet-like structures $(198,199)$ that recapitulate the function of their adult differentiated counterparts upon transplantation in mice or humanized models.

\section{Conclusion}

Despite the wide swath of redundant mechanisms that control central and peripheral tolerance, the high incidence of autoimmune diseases and difficulty restoring tolerance in humans reflect the equally powerful mechanisms that ensure effective immune responses against pathogens. Thus, multiple pathways will likely need to be targeted to restore tolerance to self antigens without compromising overall immunity (Figure 3). Tremendous progress has been made in our understanding of the pathways that control autoimmunity and defects associated with distinct autoimmune diseases, leading to many novel therapeutic approaches targeting individual pathways. Combination therapies have been introduced in clinical trials with mixed results, which emphasizes that they could be more efficacious; however, combination treatments might raise new safety challenges as well (200). In the future, cus- tomized therapies and combination therapies should be informed not only by pathways found to be important in each autoimmune disease but also by the genetic and environmental influences in each patient, as certain treatments may be predicted to have greater efficacy depending on individual genetic susceptibility and immunological history. This increased level of granularity will undoubtedly reveal additional complexity in the molecular and cellular interactions underlying autoimmunity, but it is also bound to result in improved control of autoimmune diseases in individual patients in the new era of precision medicine.

\section{Acknowledgments}

We thank members of the Bluestone and Anderson labs for contributions to the science that drove much of the commentary in this Review. This work was funded by the National Institute of Allergy and Infectious Diseases (grants R01AI046643 and R01AI097457); the National Institute of Diabetes, Digestive and Kidney Diseases (grant R01DK101622); the Juvenile Diabetes Research Foundation (grants 17-2011-661 and 17-2013-513); the JDRF Collaborative Center for Treg Biology; and the California Institute for Regeneration Medicine (grant RB5-07262).

Address correspondence to: Jeffrey Bluestone, Diabetes Center, University of California San Francisco, HSW 1112 Box 0540, 513 Parnassus Ave., San Francisco, California 94143-0540, USA. Phone: 415.514.0417; E-mail: jeff.bluestone@ucsf.edu.
1. Cotsapas C, Hafler DA. Immune-mediated disease genetics: the shared basis of pathogenesis. Trends Immunol. 2013;34(1):22-26.

2. Ueda $\mathrm{H}$, et al. Association of the T-cell regulatory gene CTLA4 with susceptibility to autoimmune disease. Nature. 2003;423(6939):506-511.

3. Todd JA, et al. Robust associations of four new chromosome regions from genomewide analyses of type 1 diabetes. Nat Genet. 2007;39(7):857-864.

4. Consortium WTCC. Genomewide association study of 14,000 cases of seven common diseases and 3,000 controls. Nature. 2007;447(7145):661-683.

5. Pugliese A, et al. The insulin gene is transcribed in the human thymus and transcription levels correlated with allelic variation at the INS VNTRIDDM2 susceptibility locus for type 1 diabetes. Nat Genet. 1997;15(3):293-297.

6. Suzuki A. Functional haplotypes of PADI4, encoding citrullinating enzyme peptidylarginine deiminase 4, are associated with rheumatoid arthritis. Nat Genet. 2003;34(4):395-402.

7. Cheng MH, Anderson MS. Monogenic autoimmunity. Annu Rev Immunol. 2012;30:393-427.

8. Wucherpfennig KW, et al. Clonal expansion and persistence of human $\mathrm{T}$ cells specific for an immunodominant myelin basic protein peptide. J Immunol. 1994;152(11):5581-5592.

9. Zhang L, Nakayama M, Eisenbarth GS. Insulin as an autoantigen in NOD/human diabetes. Curr Opin Immunol. 2008;20(1):111-118.

10. Reijonen H, et al. Detection of GAD65-specific T-cells by major histocompatibility complex class II tetramers in type 1 diabetic patients and at-risk subjects. Diabetes. 2002;51(5):1375-1382.

11. Su LF, Kidd BA, Han A, Kotzin JJ, Davis MM. Virus-specific CD4(+) memory-phenotype T cells are abundant in unexposed adults. Immunity. 2013;38(2):373-383.

12. Bour-Jordan H, Esensten JH, Martinez-Llordella M, Penaranda C, Stumpf M, Bluestone JA. Intrinsic and extrinsic control of peripheral T-cell tolerance by costimulatory molecules of the CD28/B7 family. Immunol Rev. 2011;241(1):180-205.

13. Bluestone JA. Mechanisms of tolerance. Immunol Rev. 2011;241(1):5-19.

14. Wing K, Sakaguchi S. Regulatory T cells exert checks and balances on self tolerance and autoimmunity. Nat Immunol. 2010;11(1):7-13.

15. Brusko TM, Putnam AL, Bluestone JA. Human regulatory T cells: role in autoimmune disease and therapeutic opportunities. Immunol Rev. 2008;223:371-390.

16. Sakaguchi S, Miyara M, Costantino CM, Hafler DA. FOXP3+ regulatory T cells in the human immune system. Nat Rev Immunol. 2010;10(7):490-500.

17. Bennett CL, et al. The immune dysregulation, polyendocrinopathy, enteropathy, X-linked syndrome (IPEX) is caused by mutations of FOXP3. Nat Genet. 2001;27(1):20-21.

18. Fontenot JD, Gavin MA, Rudensky AY. Foxp3 programs the development and function of CD4(+)CD25(+) regulatory T cells. Nat Immunol. 2003;4(4):330-336

19. Hori S, Nomura T, Sakaguchi S. Control of regulatory T cell development by the transcription factor Foxp3. Science. 2003;299(5609):1057-1061. 20. Wan YY, Flavell RA. Regulatory T-cell func- tions are subverted and converted owing to attenuated Foxp3 expression. Nature. 2007;445(7129):766-770.

21. Kim JM, Rasmussen JP, Rudensky AY. Regulatory $\mathrm{T}$ cells prevent catastrophic autoimmunity throughout the lifespan of mice. Nat Immunol. 2007;8(2):191-197.

22. Anderson MS, et al. Projection of an immunological self shadow within the thymus by the aire protein. Science. 2002;298(5597):1395-1401.

23. Liston A, Lesage S, Wilson J, Peltonen L, Goodnow CC. Aire regulates negative selection of organ-specific T cells. Nat Immunol. 2003;4(4):350-354.

24. Anderson MS, Su MA. Aire and T cell development. Curr Opin Immunol. 2011;23(2):198-206.

25. Perheentupa J. Autoimmune polyendocrinopathy-candidiasis-ectodermal dystrophy. J Clin Endocrinol Metab. 2006;91(8):2843-2850.

26. Taniguchi RT, et al. Detection of an autoreactive T-cell population within the polyclonal repertoire that undergoes distinct autoimmune regulator (Aire)-mediated selection. Proc Natl Acad Sci US A. 2012;109(20):7847-7852.

27. Giraud M, et al. An IRF8-binding promoter variant and AIRE control CHRNA1 promiscuous expression in thymus. Nature. 2007;448(7156):934-937.

28. Vafiadis P, et al. Insulin expression in human thymus is modulated by INS VNTR alleles at the IDDM2 locus. Nat Genet. 1997;15(3):289-292.

29. Gray D, Abramson J, Benoist C, Mathis D. Proliferative arrest and rapid turnover of thymic epithelial cells expressing Aire. J Exp Med. 2007;204(11):2521-2528. 
30. Metzger TC, et al. Lineage tracing and cell ablation identify a post-Aire-expressing thymic epithelial cell population. Cell Rep. 2013; 5(1):166-179.

31. Ucar A, et al. Adult thymus contains FoxN1(-) epithelial stem cells that are bipotent for medullary and cortical thymic epithelial lineages. Immunity. 2014;41(2):257-269.

32. Wong K, et al. Multilineage potential and self-renewal define an epithelial progenitor cell population in the adult thymus. Cell Rep. 2014;8(4):1198-1209.

33. Roberts NA, et al. Rank signaling links the development of invariant gammadelta $\mathrm{T}$ cell progenitors and Aire $(+)$ medullary epithelium. Immunity. 2012;36(3):427-437.

34. Rossi SW, et al. RANK signals from CD4(+)3(-) inducer cells regulate development of Aireexpressing epithelial cells in the thymic medulla. JExp Med. 2007;204(6):1267-1272.

35. White AJ, et al. Sequential phases in the development of Aire-expressing medullary thymic epithelial cells involve distinct cellular input. Eur J Immunol. 2008;38(4):942-947.

36. Jamieson BD, et al. Generation of functional thymocytes in the human adult. Immunity. 1999;10(5):569-575.

37. McFarland RD, Douek DC, Koup RA, Picker LJ. Identification of a human recent thymic emigrant phenotype. Proc Natl Acad Sci US A. 2000;97(8):4215-4220.

38. Wucherpfennig KW, Call MJ, Deng L, Mariuzza R. Structural alterations in peptide-MHC recognition by self-reactive T cell receptors. Curr Opin Immunol. 2009;21(6):590-595.

39. Hahn M, Nicholson MJ, Pyrdol J, Wucherpfennig KW. Unconventional topology of self peptidemajor histocompatibility complex binding by a human autoimmune T cell receptor. Nat Immunol. 2005;6(5):490-496.

40. Bulek AM, et al. Structural basis for the killing of human $\beta$ cells by $\mathrm{CD} 8^{+} \mathrm{T}$ cells in type 1 diabetes. Nat Immunol. 2012;13(3):283-289.

41. Crawford F, et al. Specificity and detection of insulin-reactive $\mathrm{CD} 4^{+} \mathrm{T}$ cells in type 1 diabetes in the nonobese diabetic (NOD) mouse. Proc Natl Acad Sci U S A. 2011;108(40):16729-16734.

42. Stadinski BD, Zhang L, Crawford F, Marrack P, Eisenbarth GS, Kappler JW. Diabetogenic T cells recognize insulin bound to IAg7 in an unexpected, weakly binding register. Proc Natl Acad Sci U S A. 2010;107(24):10978-10983.

43. Yang J, et al. Autoreactive T cells specific for insulin B:11-23 recognize a low-affinity peptide register in human subjects with autoimmune diabetes. Proc Natl Acad Sci U S A. 2014;111(41):14840-14845.

44. Mohan JF, Petzold SJ, Unanue ER. Register shifting of an insulin peptide-MHC complex allows diabetogenic $\mathrm{T}$ cells to escape thymic deletion. JExp Med. 2011;208(12):2375-2383.

45. Mohan JF, Unanue ER. A novel pathway of presentation by class II-MHC molecules involving peptides or denatured proteins important in autoimmunity. Mol Immunol. 2013; 55(2):166-168.

46. Stadinski BD, et al. Chromogranin A is an autoantigen in type 1 diabetes. Nat Immunol.
2010;11(3):225-231.

47. Li Y, Huang Y, Lue J, Quandt JA, Martin R, Mariuzza RA. Structure of a human autoimmune TCR bound to a myelin basic protein self-peptide and a multiple sclerosis-associated MHC class II molecule. EMBO J. 2005;24(17):2968-2979.

48. He XL, Radu C, Sidney J, Sette A, Ward ES, Garcia KC. Structural snapshot of aberrant antigen presentation linked to autoimmunity: the immunodominant epitope of MBP complexed with I-Au. Immunity. 2002;17(1):83-94.

49. McGinty JW, Chow IT, Greenbaum C, Odegard J, Kwok WW, James EA. Recognition of posttranslationally modified GAD65 epitopes in subjects with type 1 diabetes. Diabetes. 2014;63(9):3033-3040.

50 . Knight RR, et al. A distinct immunogenic region of glutamic acid decarboxylase 65 is naturally processed and presented by human islet cells to cytotoxic CD8 T cells. Clin Exp Immunol. 2015;179(1):100-107.

51. Wegner N. Autoimmunity to specific citrullinated proteins gives the first clues to the etiology of rheumatoid arthritis. Immunol Rev. 2010;233(1):34-54.

52. Busch R, De Riva A, Hadjinicolaou AV, Jiang W, Hou T, Mellins ED. On the perils of poor editing: regulation of peptide loading by HLADQ and H2-A molecules associated with celiac disease and type 1 diabetes. Expert Rev Mol Med. 2012;14:e15.

53. Bautista JL, et al. Intraclonal competition limits the fate determination of regulatory $\mathrm{T}$ cells in the thymus. Nat Immunol. 2009;10(6):610-617.

54. Klein L, Kyewski B, Allen PM, Hogquist KA. Positive and negative selection of the T cell repertoire: what thymocytes see (and don't see). Nat Rev Immunol. 2014;14(6):377-391.

55. Perry JS, et al. Distinct contributions of Aire and antigen-presenting-cell subsets to the generation of self-tolerance in the thymus. Immunity. 2014;41(3):414-426.

56. Aschenbrenner K, et al. Selection of Foxp3+ regulatory $\mathrm{T}$ cells specific for self antigen expressed and presented by Aire+ medullary thymic epithelial cells. Nat Immunol. 2007;8(4):351-358.

57. Malchow S, et al. Aire-dependent thymic development of tumor-associated regulatory $\mathrm{T}$ cells. Science. 2013;339(6124):1219-1224.

58. Anderson MS, Venanzi ES, Chen Z, Berzins SP, Benoist C, Mathis D. The cellular mechanism of Aire control of T cell tolerance. Immunity. 2005;23(2):227-239.

59. Kohm AP, Carpentier PA, Anger HA, Miller SD. Cutting edge: $\mathrm{CD} 4^{+} \mathrm{CD} 25^{+}$regulatory $\mathrm{T}$ cells suppress antigen-specific autoreactive immune responses and central nervous system inflammation during active experimental autoimmune encephalomyelitis. J Immunol. 2002;169(9):4712-4716.

60. Mottet C, Uhlig HH, Powrie F. Cutting edge: cure of colitis by $\mathrm{CD} 4{ }^{+} \mathrm{CD} 25^{+}$regulatory $\mathrm{T}$ cells. J Immunol. 2003;170(8):3939-3943.

61. Salomon B, et al. B7/CD28 costimulation is essential for the homeostasis of the $\mathrm{CD} 4^{+} \mathrm{CD} 25^{+}$ immunoregulatory $\mathrm{T}$ cells that control autoimmune diabetes. Immunity. 2000;12(4):431-440.

62. You S, et al. Autoimmune diabetes onset results from qualitative rather than quantitative age-dependent changes in pathogenic T-cells. Diabetes. 2005;54(5):1415-1422.

63. Schneider A, et al. In active relapsing-remitting multiple sclerosis, effector $\mathrm{T}$ cell resistance to adaptive T(regs) involves IL-6-mediated signaling. Sci Transl Med. 2013;5(170):170ra115.

64. Schenten D, et al. Signaling through the adaptor molecule MyD88 in CD4 ${ }^{+} \mathrm{T}$ cells is required to overcome suppression by regulatory $\mathrm{T}$ cells. Immunity. 2014;40(1):78-90.

65. Bour-Jordan H, Salomon BL, Thompson HL, Szot GL, Bernhard MR, Bluestone JA. Costimulation controls diabetes by altering the balance of pathogenic and regulatory $\mathrm{T}$ cells. J Clin Invest. 2004;114(7):979-987.

66. Cvetanovich GL, Hafler DA. Human regulatory T cells in autoimmune diseases. Curr Opin Immunol. 2010;22(6):753-760.

67. Buckner JH. Mechanisms of impaired regulation by $\mathrm{CD} 4^{+} \mathrm{CD} 25^{+} \mathrm{FOXP} 3^{+}$regulatory $\mathrm{T}$ cells in human autoimmune diseases. Nat Rev Immunol. 2010;10(12):849-859.

68. Long SA, et al. Defects in IL-2R signaling contribute to diminished maintenance of FOXP3 expression in $\mathrm{CD} 4(+) \mathrm{CD} 25(+)$ regulatory T-cells of type 1 diabetic subjects. Diabetes. 2010;59(2):407-415.

69. Long SA, et al. An autoimmune-associated variant in PTPN2 reveals an impairment of IL-2R signaling in CD4(+) T cells. Genes Immun. 2011;12(2):116-125

70. Cerosaletti K, et al. Multiple autoimmune-associated variants confer decreased IL-2R signaling in $\mathrm{CD} 4{ }^{+} \mathrm{CD} 25$ (hi) $\mathrm{T}$ cells of type 1 diabetic and multiple sclerosis patients. PLoS One. 2013;8(12):e83811.

71. Liu W, et al. CD127 expression inversely correlates with FoxP3 and suppressive function of human $\mathrm{CD} 4^{+} \mathrm{T}$ reg cells. J Exp Med. 2006;203(7):1701-1711.

72. Putnam AL, et al. Expansion of human regulatory T-cells from patients with type 1 diabetes. Diabetes. 2009;58(3):652-662.

73. Garg G, et al. Type 1 diabetes-associated IL2RA variation lowers IL-2 signaling and contributes to diminished $\mathrm{CD} 4{ }^{+} \mathrm{CD} 25^{+}$regulatory $\mathrm{T}$ cell function. JImmunol. 2012;188(9):4644-4653.

74. Lindley S, Dayan CM, Bishop A, Roep BO, Peakman M, Tree TI. Defective suppressor function in CD4(+)CD25(+) T-cells from patients with type 1 diabetes. Diabetes. 2005;54(1):92-99.

75. Zhou X, et al. Selective miRNA disruption in T reg cells leads to uncontrolled autoimmunity. JExp Med. 2008;205(9):1983-1991.

76. Tang $\mathrm{Q}$, et al. Central role of defective interleukin-2 production in the triggering of islet autoimmune destruction. Immunity 2008;28(5):687-697.

77. Hsieh CS, Liang Y, Tyznik AJ, Self SG, Liggitt D, Rudensky AY. Recognition of the peripheral self by naturally arising $\mathrm{CD} 25^{+} \mathrm{CD} 4^{+} \mathrm{T}$ cell receptors. Immunity. 2004;21(2):267-277.

78. Jordan MS, et al. Thymic selection of CD $4^{+} \mathrm{CD} 25$ regulatory $\mathrm{T}$ cells induced by an agonist selfpeptide. Nat Immunol. 2001;2(4):301-306.

79. Abbas AK, et al. Regulatory T cells: recommendations to simplify the nomenclature. Nat Immunol. 
2013;14(4):307-308.

80. Bluestone JA, Abbas AK. Natural versus adaptive regulatory T cells. Nat Rev Immunol. 2003;3(3):253-257.

81. Yadav M, Stephan S, Bluestone JA. Peripherally induced tregs - role in immune homeostasis and autoimmunity. Front Immunol. 2013;4:232.

82. Apostolou I, Sarukhan A, Klein L, Von Boehmer H. Origin of regulatory $\mathrm{T}$ cells with known specificity for antigen. Nat Immunol. 2002;3(8):756-763.

83. Corse E, Gottschalk RA, Allison JP. Strength of TCR-peptide/MHC interactions and in vivo T cell responses. JImmunol. 2011;186(9):5039-5045.

84. Coombes JL, et al. A functionally specialized population of mucosal $\mathrm{CD} 103^{+}$DCs induces Foxp $3^{+}$regulatory T cells via a TGF- $\beta$ and retinoic acid-dependent mechanism. J Exp Med. 2007;204(8):1757-1764.

85. Li MO, Sanjabi S, Flavell RA. Transforming growth factor-beta controls development, homeostasis, and tolerance of $\mathrm{T}$ cells by regulatory $\mathrm{T}$ cell-dependent and -independent mechanisms. Immunity. 2006;25(3):455-471.

86. Sun CM, et al. Small intestine lamina propria dendritic cells promote de novo generation of Foxp3 T reg cells via retinoic acid. J Exp Med. 2007;204(8):1775-1785.

87. Mucida D, et al. Reciprocal TH17 and regulatory $T$ cell differentiation mediated by retinoic acid. Science. 2007;317(5835):256-260.

88. Lathrop SK, et al. Peripheral education of the immune system by colonic commensal microbiota. Nature. 2011;478(7368):250-254.

89. Atarashi K, et al. Treg induction by a rationally selected mixture of Clostridia strains from the human microbiota. Nature. 2013;500(7461):232-236.

90. Arpaia N, et al. Metabolites produced by commensal bacteria promote peripheral regulatory $\mathrm{T}$-cell generation. Nature. 2013;504(7480):451-455.

91. Furusawa Y, et al. Commensal microbe-derived butyrate induces the differentiation of colonic regulatory T cells. Nature. 2013;504(7480):446-450.

92. Yadav M, Stephan S, Bluestone JA. Peripherally induced tregs - role in immune homeostasis and autoimmunity. Front Immunol. 2013;4:232.

93. Haribhai D, et al. A central role for induced regulatory $\mathrm{T}$ cells in tolerance induction in experimental colitis. J Immunol. 2009;182(6):3461-3468.

94. Haribhai D, et al. A requisite role for induced regulatory T cells in tolerance based on expanding antigen receptor diversity. Immunity. 2011;35(1):109-122.

95. Josefowicz SZ, et al. Extrathymically generated regulatory $\mathrm{T}$ cells control mucosal TH2 inflammation. Nature. 2012;482(7385):395-399.

96. Yadav M, et al. Neuropilin-1 distinguishes natural and inducible regulatory $\mathrm{T}$ cells among regulatory T cell subsets in vivo. J Exp Med. 2012;209(10):1713-1722.

97. Pacholczyk R, Ignatowicz H, Kraj P, Ignatowicz L. Origin and $\mathrm{T}$ cell receptor diversity of $\mathrm{Foxp}^{+} \mathrm{C}-$ D $4^{+} \mathrm{CD} 25^{+} \mathrm{T}$ cells. Immunity. 2006;25(2):249-259.

98. Hsieh CS, Zheng Y, Liang Y, Fontenot JD, Rudensky AY. An intersection between the self-reactive regulatory and nonregulatory $\mathrm{T}$ cell receptor repertoires. Nat Immunol. 2006;7(4):401-410.
99. Wong J, Obst R, Correia-Neves M, Losyev G, Mathis D, Benoist C. Adaptation of TCR repertoires to self-peptides in regulatory and nonregulatory $\mathrm{CD}^{+} \mathrm{T}$ cells. J Immunol. 2007;178(11):7032-7041.

100.Samy ET, Parker LA, Sharp CP, Tung KS. Continuous control of autoimmune disease by antigen-dependent polyclonal $\mathrm{CD} 4^{+} \mathrm{CD} 25^{+}$regulatory $\mathrm{T}$ cells in the regional lymph node. J Exp Med. 2005;202(6):771-781.

101.Seddon B, Mason D. Peripheral autoantigen induces regulatory $\mathrm{T}$ cells that prevent autoimmunity. JExp Med.1999;189(5):877-882.

102.Zhou X, et al. Instability of the transcription factor Foxp3 leads to the generation of pathogenic memory T cells in vivo. Nat Immunol. 2009;10(9):1000-1007.

103. Bailey-Bucktrout SL, Bluestone JA. Regulatory T cells: stability revisited. Trends Immunol. 2011;32(7):301-306

104.Beriou G, et al. IL-17-producing human peripheral regulatory $\mathrm{T}$ cells retain suppressive function. Blood. 2009;113(18):4240-4249.

105. Voo KS, et al. Identification of IL-17-producing $\mathrm{FOXP}^{+}$regulatory T cells in humans. Proc Natl Acad Sci U S A. 2009;106(12):4793-4798.

106.Komatsu N, et al. Pathogenic conversion of Foxp $3^{+} \mathrm{T}$ cells into TH17 cells in autoimmune arthritis. Nat Med. 2014;20(1):62-68.

107. Rubtsov YP, et al. Stability of the regulatory T cell lineage in vivo. Science. 2010;329(5999):1667-1671.

108. Miyao T, et al. Plasticity of Foxp3(+) T cells reflects promiscuous Foxp3 expression in conventional T cells but not reprogramming of regulatory T cells. Immunity. 2012;36(2):262-275.

109. Bailey-Bucktrout SL, et al. Self-antigen-driven activation induces instability of regulatory $\mathrm{T}$ cells during an inflammatory autoimmune response. Immunity. 2013;39(5):949-962.

110. McClymont SA, et al. Plasticity of human regulatory T cells in healthy subjects and patients with type 1 diabetes. J Immunol. 2011;186(7):3918-3926.

111. Dominguez-Villar M, Baecher-Allan CM, Hafler DA. Identification of T helper type 1-like, Foxp $3^{+}$ regulatory $\mathrm{T}$ cells in human autoimmune disease. Nat Med. 2011;17(6):673-675.

112. Gavin MA, et al. Foxp3-dependent programme of regulatory T-cell differentiation. Nature. 2007;445(7129):771-775.

113. Bour-Jordan H, Bluestone JA. Regulating the regulators: costimulatory signals control the homeostasis and function of regulatory T cells. Immunol Rev. 2009;229(1):41-66.

114. Tang Q, et al. Cutting edge: CD28 controls peripheral homeostasis of $\mathrm{CD} 4^{+} \mathrm{CD} 25^{+}$regulatory T cells. J Immunol. 2003;171(7):3348.

115. Josefowicz SZ, Rudensky A. Control of regulatory T cell lineage commitment and maintenance. Immunity. 2009;30(5):616-625.

116. Rudensky AY. Regulatory T cells and Foxp3. Immunol Rev. 2011;241(1):260-268.

117. Barron L, et al. Cutting edge: mechanisms of IL-2-dependent maintenance of functional regulatory T cells. J Immunol. 2010;185(11):6426-6430.

118. Levine AG, Arvey A, Jin W, Rudensky AY. Continuous requirement for the TCR in regulatory $\mathrm{T}$ cell function. Nat Immunol. 2014;15(11):1070-1078.
119. Cheng G, Yu A, Malek TR. T-cell tolerance and the multi-functional role of IL-2R signaling in T-regulatory cells. Immunol Rev. 2011;241(1):63-76.

120. Baron U, et al. DNA demethylation in the human FOXP3 locus discriminates regulatory $\mathrm{T}$ cells from activated FOXP3(+) conventional T cells. Eur J Immunol. 2007;37(9):2378-2389.

121. Floess S, et al. Epigenetic control of the foxp3 locus in regulatory T cells. PLoS Biol. 2007;5(2):e38

122. Polansky JK, et al. DNA methylation controls Foxp3 gene expression. Eur JImmunol. 2008;38(6):1654-1663

123. Feng Y, Arvey A, Chinen T, van der Veeken J, Gasteiger G, Rudensky AY. Control of the inheritance of regulatory $\mathrm{T}$ cell identity by a cis element in the Foxp3 locus. Cell. 2014;158(4):749-763.

124.Li X, Liang Y, LeBlanc M, Benner C, Zheng Y. Function of a Foxp3 cis-element in protecting regulatory T cell identity. Cell. 2014;158(4):734-748.

125. Bluestone JA, Bour-Jordan H. Current and future immunomodulation strategies to restore tolerance in autoimmune diseases. Cold Spring Harb Perspect Biol. 2012;4(11):a007542.

126. van de Linde P, et al. Mechanisms of antibody immunotherapy on clonal islet reactive T cells. Hum Immunol. 2006;67(4):264-273.

127. Tang Q, Bluestone JA. The Foxp $3^{+}$regulatory T cell: a jack of all trades, master of regulation. Nat Immunol. 2008;9(3):239-244.

128. Herold KC, Vignali DA, Cooke A, Bluestone JA. Type 1 diabetes: translating mechanistic observations into effective clinical outcomes. Nat Rev Immunol. 2013;13(4):243-256.

129. Saudek F, Havrdova T, Boucek P, Karasova L, Novota P, Skibova J. Polyclonal anti-T-cell therapy for type 1 diabetes mellitus of recent onset. Rev Diabet Stud. 2004;1(2):80-88.

130.Simon G, et al. Murine antithymocyte globulin therapy alters disease progression in NOD mice by a time-dependent induction of immunoregulation. Diabetes. 2008;57(2):405-414.

131. Feng $X$, et al. Rabbit ATG but not horse ATG promotes expansion of functional $\mathrm{CD} 4{ }^{+} \mathrm{CD} 25^{\text {high }} \mathrm{FOXP} 3^{+}$regulatory $\mathrm{T}$ cells in vitro. Blood. 2008;111(7):3675-3683.

132. Lopez M, Clarkson MR, Albin M, Sayegh MH, Najafian N. A novel mechanism of action for anti-thymocyte globulin: induction of $\mathrm{CD}^{+} \mathrm{CD} 25^{+} \mathrm{Foxp}^{+}$regulatory T cells. J Am Soc Nephrol. 2006;17(10):2844-2853.

133. Gitelman SE, et al. Antithymocyte globulin treatment for patients with recent-onset type 1 diabetes: 12-month results of a randomised, placebo-controlled, phase 2 trial. Lancet Diabetes Endocrinol.2013;1(4):306-316.

134. Haller MJ, et al. Anti-thymocyte globulin/G-CSF treatment preserves $\beta$ cell function in patients with established type 1 diabetes. JClin Invest. 2015;125(1):448-455

135. Laughlin E, Burke G, Pugliese A, Falk B, Nepom G. Recurrence of autoreactive antigen-specific CD 4 T cells in autoimmune diabetes after pancreas transplantation. Clin Immunol. 2008;128(1):23-30.

136. Vendrame F, et al. Recurrence of type 1 diabetes after simultaneous pancreas-kidney transplantation, despite immunosuppression, is associated with autoantibodies and pathogenic autoreactive 
CD4 T-cells. Diabetes. 2010;59(4):947-957.

137. Jones JL, et al. Human autoimmunity after lymphocyte depletion is caused by homeostatic T-cell proliferation. Proc Natl Acad Sci U S A. 2013;110(50):20200-20205

138. Turner MJ, et al. Immune status following alemtuzumab treatment in human CD52 transgenic mice. J Neuroimmunol. 2013;261(1):29-36.

139. Zhang X, et al. Differential reconstitution of $\mathrm{T}$ cell subsets following immunodepleting treatment with alemtuzumab (anti-CD52 monoclonal antibody) in patients with relapsing-remitting multiple sclerosis. JImmunol. 2013;191(12):5867-5874 .

140. Havrdova E, Horakova D, Kovarova I. Alemtuzumab in the treatment of multiple sclerosis: key clinical trial results and considerations for use. Ther Adv Neurol Disord. 2015;8(1):31-45.

141. Chamian F, et al. Alefacept (anti-CD2) causes a selective reduction in circulating effector memory $\mathrm{T}$ cells (Tem) and relative preservation of central memory T cells (Tcm) in psoriasis. J Transl Med. 2007;5:27.

142. Weaver TA, et al. Alefacept promotes co-stimulation blockade based allograft survival in nonhuman primates. Nat Med. 2009;15(7):746-749.

143. Gottlieb AB, et al. CD4+ T-cell-directed antibody responses are maintained in patients with psoriasis receiving alefacept: results of a randomized study. J Am Acad Dermatol. 2003;49(5):816-825.

144.Krueger GG, Ellis CN. Alefacept therapy produces remission for patients with chronic plaque psoriasis. Br J Dermatol. 2003;148(4):784-788.

145. Ellis CN, Krueger GG, Alefacept Clinical Study G. Treatment of chronic plaque psoriasis by selective targeting of memory effector T lymphocytes. N Engl J Med. 2001;345(4):248-255.

146.Rigby MR, et al. Targeting of memory T cells with alefacept in new-onset type 1 diabetes (T1DAL study): 12 month results of a randomised, double-blind, placebo-controlled phase 2 trial. Lancet Diabetes Endocrinol. 2013;1(4):284-294.

147. Herold KC, et al. Treatment of patients with new onset Type 1 diabetes with a single course of anti-CD3 mAb Teplizumab preserves insulin production for up to 5 years. Clin Immunol. 2009;132(2):166-173.

148.Herold KC, et al. Teplizumab (anti-CD3 mAb) treatment preserves $\mathrm{C}$-peptide responses in patients with new-onset type 1 diabetes in a randomized controlled trial: metabolic and immunologic features at baseline identify a subgroup of responders. Diabetes. 2013;62(11):3766-3774

149. Herold KC, et al. Anti-CD3 monoclonal antibody in new-onset type 1 diabetes mellitus. $N$ EnglJMed. 2002;346(22):1692-1698.

150.Keymeulen B, et al. Insulin needs after CD3-antibody therapy in new-onset type 1 diabetes. N Engl J Med. 2005;352(25):2598-2608.

151. Belghith M, Bluestone JA, Barriot S, Megret J, Bach JF, Chatenoud L. TGF- $\beta$-dependent mechanisms mediate restoration of self-tolerance induced by antibodies to $\mathrm{CD} 3$ in overt autoimmune diabetes. Nat Med. 2003;9(9):1202-1208.

152. Herold KC, Burton JB, Francois F, Poumian-Ruiz E, Glandt M, Bluestone JA. Activation of human $\mathrm{T}$ cells by FcR nonbinding antiCD3 mAb, hOKT3r1(Ala-Ala). J Clin Invest. 2003;111(3):409-418.
153. Penaranda C, Tang Q, Bluestone JA. Anti-CD3 therapy promotes tolerance by selectively depleting pathogenic cells while preserving regulatory T cells. JImmunol. 2011;187(4):2015-2022.

154. Ochi H, et al. Oral CD3-specific antibody suppresses autoimmune encephalomyelitis by inducing $\mathrm{CD} 4{ }^{+} \mathrm{CD} 25^{-} \mathrm{LAP}+\mathrm{T}$ cells. Nat Med 2006;12(6):627-635.

155. Waldron-Lynch F, et al. Teplizumab induces human gut-tropic regulatory cells in humanized mice and patients. Sci Transl Med. 2012;4(118):118ra112.

156.Samson MF, Smilek DE. Reversal of acute experimental autoimmune encephalomyelitis and prevention of relapses by treatment with a myelin basic protein peptide analogue modified to form long-lived peptide-MHC complexes. J Immunol. 1995;155(5):2737-2746.

157. Smilek DE, Wraith DC, Hodgkinson S, Dwivedy S, Steinman L, McDevitt HO. A single amino acid change in a myelin basic protein peptide confers the capacity to prevent rather than induce experimental autoimmune encephalomyelitis. Proc Natl Acad Sci U S A. 1991;88(21):9633-9637.

158. Tian J, et al. Modulating autoimmune responses to GAD inhibits disease progression and prolongs islet graft survival in diabetes-prone mice. Nat Med. 1996;2(12):1348-1353.

159. Zhang ZJ, Davidson L, Eisenbarth G, Weiner HL. Suppression of diabetes in nonobese diabetic mice by oral administration of porcine insulin. Proc Natl Acad Sci U S A. 1991;88(22):10252-10256.

160.Hjorth M, Axelsson S, Ryden A, Faresjo M, Ludvigsson J, Casas R. GAD-alum treatment induces GAD65-specific $\mathrm{CD} 4{ }^{+} \mathrm{CD} 25^{\text {high }} \mathrm{FOXP}^{+}$ cells in type 1 diabetic patients. Clin Immunol. 2011;138(1):117-126.

161. Orban T, et al. Autoantigen-specific regulatory $\mathrm{T}$ cells induced in patients with type 1 diabetes mellitus by insulin B-chain immunotherapy. JAutoimmun. 2010;34(4):408-415.

162.Prakken BJ, et al. Epitope-specific immunotherapy induces immune deviation of proinflammatory T cells in rheumatoid arthritis. Proc Natl Acad Sci U S A. 2004;101(12):4228-4233.

163. Thrower SL, et al. Proinsulin peptide immunotherapy in type 1 diabetes: report of a firstin-man Phase I safety study. Clin Exp Immunol. 2009;155(2):156-165.

164. Vandenbark AA, Vainiene M, Ariail K, Miller SD, Offner H. Prevention and treatment of relapsing autoimmune encephalomyelitis with myelin peptide-coupled splenocytes. JNeurosci Res. 1996;45(4):430-438.

165. Fife BT, et al. Insulin-induced remission in new-onset NOD mice is maintained by the PD-1-PD-L1 pathway. J Exp Med. 2006;203(12):2737-2747.

166.Smith CE, Miller SD. Multi-peptide coupled-cell tolerance ameliorates ongoing relapsing EAE associated with multiple pathogenic autoreactivities. JAutoimmunity. 2006;27(4):218-231.

167. Niens M, Grier AE, Marron M, Kay TW, Greiner DL, Serreze DV. Prevention of "Humanized" diabetogenic CD8 T-cell responses in HLA-transgenic NOD mice by a multipeptide coupled-cell approach. Diabetes. 2011;60(4):1229-1236.

168. Lutterotti A, et al. Antigen-specific tolerance by autologous myelin peptide-coupled cells: a phase 1 trial in multiple sclerosis. Sci Transl Med. 2013;5(188):188ra175.

169. Wang X, et al. Mechanism of oral tolerance induction to therapeutic proteins. Adv Drug Deliv Rev. 2013;65(6):759-773.

170.Skyler JS, et al. Effects of oral insulin in relatives of patients with type 1 diabetes: The Diabetes Prevention Trial - Type 1. Diabetes care. 2005;28(5):1068-1076.

171. Bayer AL, Pugliese A, Malek TR. The IL-2/IL-2R system: from basic science to therapeutic applications to enhance immune regulation. Immunol Res. 2013;57(1):197-209.

172. Grinberg-Bleyer Y, et al. IL-2 reverses established type 1 diabetes in NOD mice by a local effect on pancreatic regulatory T cells. J Exp Med. 2010;207(9):1871.

173. Hartemann A, et al. Low-dose interleukin 2 in patients with type 1 diabetes: a phase $1 / 2$ randomised, double-blind, placebo-controlled trial. Lancet Diabetes Endocrinol. 2013;1(4):295-305.

174. Boyman O, Kovar M, Rubinstein MP, Surh CD, Sprent J. Selective stimulation of T cell subsets with antibody-cytokine immune complexes. Science. 2006;311(5769):1924-1927.

175. Baeyens A, et al. Limitations of IL-2 and rapamycin in immunotherapy of type 1 diabetes. Diabetes. 2013;62(9):3120-3131.

176. Battaglia M, Stabilini A, Roncarolo MG. Rapamycin selectively expands $\mathrm{CD} 4{ }^{+} \mathrm{CD} 25^{+} \mathrm{FoxP}^{+}$regulatory T cells. Blood. 2005;105(12):4743-4748.

177. Delgoffe GM, et al. The mTOR kinase differentially regulates effector and regulatory $\mathrm{T}$ cell lineage commitment. Immunity. 2009;30(6):832-844.

178. Delgoffe GM, et al. The kinase mTOR regulates the differentiation of helper $\mathrm{T}$ cells through the selective activation of signaling by $\mathrm{mTORC} 1$ and mTORC2. Nat Immunol. 2011;12(4):295-303.

179. Long SA, et al. Rapamycin/IL-2 combination therapy in patients with type 1 diabetes augments Tregs yet transiently impairs beta-cell function. Diabetes. 2012;61(9):2340-2348.

180. Levin AM, et al. Exploiting a natural conformational switch to engineer an interleukin-2 'superkine'. Nature. 2012;484(7395):529-533.

181. Wang X, Rickert M, Garcia KC. Structure of the quaternary complex of interleukin-2 with its $\alpha, \beta$, and $\gamma c$ receptors. Science. 2005;310(5751):1159-1163.

182.Tang Q, Bluestone JA. Regulatory T-cell therapy in transplantation: moving to the clinic. Cold Spring Harb Perspect Med. 2013;3(11):a015552.

183.Bluestone JA, Tang Q. Therapeutic vaccination using $\mathrm{CD}^{+} \mathrm{CD} 25^{+}$antigen-specific regulatory T cells. Proc Natl Acad Sci U S A. 2004;101(suppl 2):14622-14626.

184. Tang $\mathrm{Q}$, et al. In vitro-expanded antigen-specific regulatory $\mathrm{T}$ cells suppress autoimmune diabetes. JExp Med.2004;199(11):1455-1465.

185. Scalapino KJ, Tang Q, Bluestone JA, Bonyhadi ML, Daikh DI. Suppression of disease in New Zealand Black/New Zealand White lupus-prone mice by adoptive transfer of ex vivo expanded regulatory T cells. JImmunol. 2006;177(3):1451-1459.

186. Chai JG, Coe D, Chen D, Simpson E, Dyson J, Scott D. In vitro expansion improves in vivo regulation by $\mathrm{CD} 4^{+} \mathrm{CD} 25^{+}$regulatory $\mathrm{T}$ cells. J Immunol. 2008;180(2):858-869. 
187. Putnam AL, et al. Clinical grade manufacturing of human alloantigen-reactive regulatory $\mathrm{T}$ cells for use in transplantation. Am J Transplant. 2013;13(11):3010-3020.

188. Marek-Trzonkowska N, et al. Therapy of type 1 diabetes with CD4(+)CD25(high)CD127regulatory $\mathrm{T}$ cells prolongs survival of pancreatic islets - results of one year follow-up. Clin Immunol. 2014;153(1):23-30.

189. Masteller EL, Tang Q, Bluestone JA. Antigen-specific regulatory $\mathrm{T}$ cells - ex vivo expansion and therapeutic potential. Semin Immunol. 2006;18(2):103-110.

190. Mekala DJ, Geiger TL. Immunotherapy of autoimmune encephalomyelitis with redirected $\mathrm{CD} 4{ }^{+} \mathrm{CD} 25^{+} \mathrm{T}$ lymphocytes. Blood. 2005;105(5):2090-2092.

191. Brusko TM, et al. Human antigen-specific regulatory $\mathrm{T}$ cells generated by $\mathrm{T}$ cell receptor gene transfer. PLoS One. 2010;5(7):e11726.

192.Elinav E, Adam N, Waks T, Eshhar Z. Amelioration of colitis by genetically engineered murine regulatory $\mathrm{T}$ cells redirected by antigen-specific chimeric receptor. Gastroenterology. 2009;136(5):1721-1731.

193. Hombach AA, Kofler D, Rappl G, Abken H. Redirecting human $\mathrm{CD} 4{ }^{+} \mathrm{CD} 25^{+}$regulatory $\mathrm{T}$ cells from the peripheral blood with pre-defined target specificity. Gene Ther. 2009;16(9):1088-1096.

194. Chidgey AP, Layton D, Trounson A, Boyd RL. Tolerance strategies for stem-cell-based therapies. Nature. 2008;453(7193):330-337.

195. Nobori S, et al. Long-term acceptance of fully allogeneic cardiac grafts by cotransplantation of vascularized thymus in miniature swine. Transplantation. 2006;81(1):26-35.

196. Parent AV, et al. Generation of functional thymic epithelium from human embryonic stem cells that supports host T cell development. Cell Stem Cell. 2013;13(2):219-229.

197. Sun X, et al. Directed differentiation of human embryonic stem cells into thymic epithelial progenitor-like cells reconstitutes the thymic microenvironment in vivo. Cell Stem Cell. 2013;13(2):230-236.

198. Kroon E, et al. Pancreatic endoderm derived from human embryonic stem cells generates glucose-responsive insulin-secreting cells in vivo. Nat Biotechnol. 2008;26(4):443-452.

199.Szot GL, et al. Tolerance induction and reversal of diabetes in mice transplanted with human embryonic stem cell-derived pancreatic endoderm. Cell Stem Cell. 2015;16(2):148-157.

200.Smilek DE, Ehlers MR, Nepom GT. Restoring the balance: immunotherapeutic combinations for autoimmune disease. Dis Model Mech. 2014;7(5):503-513. 